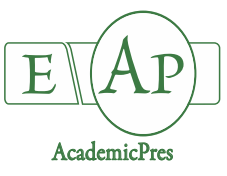

Aurori A et al. (2020)

Notulae Botanicae Horti Agrobotanici Cluj-Napoca 48(1):150-161

DOI:10.15835/nbha48111591

Research Article

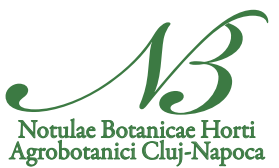

\title{
The effect of auxins in inducing organogenesis or somatic embryogenesis in mature sunflower zygotic embryo derived apex
}

\author{
Adriana AURORI ${ }^{1,2 *}$, Imola MOLNAR ${ }^{2}$, Elena RAKOSY-TICAN ${ }^{2}$ \\ ${ }^{1}$ University of Agricultural Science and Veterinary Medicine, Advanced Horticultural Research Institute of Transylvania, Microbiology \\ and Biotechnology Department, 3-5 Calea Mănăş̧tur, 400372, Cluj-Napoca, \\ Romania; aaurori2002@gmail.com (*corresponding author) \\ ${ }^{2}$ Babeş-Bolyai University, Faculty of Biology and Geology, Plant Genetic Engineering Group, 5-7 Clinicilor, 400006, Cluj-Napoca, \\ Romania;molnar.imola5@gmail.com,arina5744@yahoo.com
}

\begin{abstract}
Induction of shoots or of somatic embryos is the key step for gaining the morphogenetic potential in sunflower (Helianthus annuus L.), species known as recalcitrant to in vitro regeneration. In the immature zygotic embryo derived tissues or in other juvenile tissues resulted from seedlings, the acquisition of the competence for regeneration can be achieved directly by cytokinin treatment or by preconditioning the explants on cytokinin containing medium. In this paper is presented a new type of explant for sunflower in vitro culture, consisting of the apex with primordial leaves, resulted from ungerminated mature zygotic embryo, in which a specific morphogenetic response was triggered by the exogenously applied auxins. Among the auxins tested, indole-3-acetic acid, indole-3-butyric acid and 1-naphthaleneacetic acid are inducers of an organogenetic response, apical/axillary shoots and adventitious buds being regenerated while 2,4dichlorophenoxyacetic acid, 3,6-dichloro-2-methoxybenzoic acid and 4-amino-3,5,6-trichloropicolinic acid led to somatic embryo formation. Among the auxins tested only 4-amino-3,5,6-trichloropicolinic acid sustains the embryos development up to mature stage. A high amount of sucrose $\left(120 \mathrm{~g} \mathrm{~L}^{-1}\right)$ supplied during the auxin treatment promotes the maturation of the embryos directly on the induction medium for all tested auxins with embryogenic effect. These findings show that regardless of the type of morphogenetic response aimed in sunflower meristematic tissues resulted from mature embryos, the presence of auxins is mandatory.

Keywords: apex with primordial leaves; ungerminated mature embryo

Abbreviations: 4-amino-3,5,6-trichloropicolinic (picloram); apex with primordial leaves (A-PL); auxins inducers of embryogenesis (AIE); auxins inducers of organogenesis (AIO); 3,6-dichloro-2methoxybenzoic acid (dicamba); 2,4-dichlorophenoxyacetic acid (2,4-D); immature zygotic embryo (IZE); indole-3-acetic acid (IAA); indole-3-butyric acid (IBA); 1-naphthaleneacetic acid (NAA)
\end{abstract}

\section{Introduction}

In plant tissue culture the induction can be defined as the key step in which a group of cells, under the influence of external stimulus, become competent for morphogenesis (Potrykus, 1990). Further in the process the cell can become determined either for caulogenesis, during which unipolar structures are formed, named 
adventitious buds, or for embryogenesis, in which bipolar structures arise, the somatic embryos (Christianson and Warnick, 1983). Both ways of regeneration are equally valuable for biotechnological application in crop improvement programs (Kumar and Srivastava, 2015).

Despite of the numerous regeneration protocols established, sunflower continues to be considered a recalcitrant species to in vitro culture (Radonic et al., 2015). For improving sunflower traits by genetic transformation, gene editing techniques or other biotechnological tools, the induction of competent cells for efficient plant regeneration is mandatory (Lewi et al., 2006). Very often, depending on the genotype, the only explants which responded in culture were derived from immature zygotic embryo (IZE) (Finer, 1987; Power, 1987). Even if their morphogenetic potential has been proven, the age and size of the IZE are considered critical for the efficiency of regeneration (Witrzens et al., 1988; Espinasse et al., 1989; Sujatha and Prabakaran, 2001). This requirement makes them even more difficult to obtain, the entire process being laborious and time consuming (Sujatha et al., 2012). For one particular sunflower genotype, the inbred line HA 300B, the IZE has become a valuable experimental model, both types of regeneration can be alternatively induced by the interplays between the osmolarity of the medium due to the supplied carbon source (Bronner et al., 1994; Jeannin et al., 1995; Jeannin et al., 1998) and the endogenous and exogenous growth regulators (Charriere and Hahne, 1998). However, in the routinely developed protocols for sunflower regeneration, IZE derived explants have the tendency to develop somatic embryos (Finer, 1987; Freyssinet and Freyssinet, 1988; Fiore et al., 1997; Sujatha and Prabakaran, 2001). In the case of using explants from mature germinated seeds such are embryonic axis (Paterson, 1984; Power, 1987; Konov et al., 1998; Hewezi et al., 2003), cotyledons (Knittel et al., 1991; Sujatha et al., 2012) and hypocotyls (Ozyigit et al., 2002) organogenesis predominates, despite of the numerous combinations and types of the growth regulators applied. Only a few protocols were established for inducing organogenesis in sunflower young leaves (Paterson, 1984; Power, 1987; Konov et al., 1998; Shin et al., 2000; Zhang and Finer, 2015), but to the best of our knowledge there is no method for inducing embryogenesis in leaves. In primordial leaves resulted from germinated seeds the age of explant was an important factor, the buds regeneration efficiency decreasing with the increase of the explant age (Shin et al., 2000). Also, for inducing shoots in an efficient manner from primary leaves of the young seedlings (7 days old) (Zhang and Finer, 2015) or from the young leaves resulted from the embryonic axis (Konov et al., 1998), the originating explants had to be preconditioned on cytokinin-containing medium.

Although morphogenesis was possible in sunflower tissues resulted from immature embryos (Freyssinet and Freyssinet, 1988; Bronner et al., 1994), germinated mature seeds (Paterson, 1984) or seedlings (Konov et al., 1998; Shin et al., 2000), on medium free of auxins, these compounds were considered, sometimes empirically, without preliminary tests, as necessary for inducing caulogenesis or embryogenesis in in vitro culture of sunflower. The requirements for exogenously applied auxin may depend on: genotype (Espinasse et al., 1989), the presence of other growth regulators (Power, 1987; Espinasse et al., 1989; Sujatha and Prabakaran, 2001; Sujatha et al., 2012), the osmolarity of the medium / sucrose supply (Finer, 1987; Charriere and Hahne, 1998), the age and type of the explant and the regeneration step (Fiore et al., 1997; Freyssinet and Freyssinet, 1988; Dhaka and Kothari, 2002). The specificity of the auxin type, as the solely controlling factor, for inducing a certain response in sunflower tissue culture was not emphasized. To our knowledge, auxins lead to different responses in relation to the age and type of the explants and to the culture media. For instance, IAA led to somatic embryogenesis or organogenesis (Charriere and Hahne, 1998; Dhaka and Kothari, 2002), while dicamba triggered both types of responses (Finer, 1987; Charriere and Hahne, 1998).

The aim of this study was to investigate the morphogenetic potential of a new type of explant, the apex with primordial leaves (A-PL), resulted from ungerminated mature zygotic embryos (UMZE), under various auxin treatments. The presence of auxins was necessary for inducing the competence for regeneration, which is considered the most important feature for biotechnological improvement of sunflower. Regarding the type of 
152

the triggered morphogenetic response, the auxins were grouped in inducers of organogenesis (AIO) and inducers of embryogenesis (AIE).

\section{Materials and Methods}

\section{In vitro culture}

Mature seeds of sunflower (Helianthus annuus L., cultivar 'Florina'), provided by the National Agricultural Research and Development Institute, Fundulea, Romania, were randomly selected for excising the A-PL. The peeled seeds were sterilized following a previously described method (Rakosy-Tican et al., 2007). The aseptic seeds were soaked in distilled water for about $2 \mathrm{~h}$. For preparing the explants, the translucent seed coat and the thin endosperm were carefully removed and one of the cotyledons was discarded with caution not to wound the apex (Figure 1a - d). With the tip of a blade scalpel the A-PL (approximately $300 \mu \mathrm{m}$ in length), was carefully sectioned and placed on the surface of the culture media.

The basal culture medium consists of Murashige and Skoog (1962) supplemented with $1 \mathrm{mg} \mathrm{L}^{-1} \mathrm{~B}_{1}$ vitamin, $100 \mathrm{mg} \mathrm{L}^{-1}$ myo-inozitol, $100 \mathrm{mg} \mathrm{L}^{-1}$ peptone, $50 \mathrm{mg} \mathrm{L}^{-1}$ yeast extract, $0.1 \mathrm{mg} \mathrm{L}^{-1}$ kinetin, $0.05 \mathrm{mg} \mathrm{L}^{-1}$ $\mathrm{GA}_{3}, 100 \mathrm{mg} \mathrm{L}^{-1}$ ammonium succinate, $5 \mathrm{~g} \mathrm{~L}^{-1} \mathrm{KNO}_{3}, 6 \mathrm{~g} \mathrm{~L}^{-1}$ agar, and $30 \mathrm{~g} \mathrm{~L}^{-1}$ sucrose (Nagy and Maliga, 1976). The auxins were added individually, after media sterilization, in different concentrations as follows: IAA $(0.5$, 1 and $\left.2 \mathrm{mg} \mathrm{L}^{-1}\right)$, NAA $\left(0.5,1\right.$ and $\left.2 \mathrm{mg} \mathrm{L}^{-1}\right), \operatorname{IBA}\left(0.5,1\right.$ and $\left.2 \mathrm{mg} \mathrm{L}^{-1}\right), 2.4-\mathrm{D}\left(1,2,5\right.$ and $\left.10 \mathrm{mg} \mathrm{L}^{-1}\right)$, picloram (5 and $\left.10 \mathrm{mg} \mathrm{L}^{-1}\right)$ and dicamba $\left(1,2,5\right.$ and $\left.10 \mathrm{mg} \mathrm{L}^{-1}\right)$, as shown in Table 1 . Certain auxin treatments $(0.5$ and $1 \mathrm{mg} \mathrm{L}^{-1}$ IAA, $1 \mathrm{mg} \mathrm{L}^{-1} 2.4-\mathrm{D}, 2 \mathrm{mg} \mathrm{L}^{-1}$ dicamba, 2 and $5 \mathrm{mg} \mathrm{L}^{-1}$ picloram) were also tested in combination with a high amount of sucrose $\left(120 \mathrm{~g} \mathrm{~L}^{-1}\right)$ (Table 1$)$. The medium without auxins was considered the control. The cultures were maintained in a climate chamber in the dark at $25^{\circ} \mathrm{C}$.

Table 1. The concentrations of the auxins used individually in the basal medium containing 30 or $120 \mathrm{~g} \mathrm{~L}^{-1}$ sucrose

\begin{tabular}{|l|c|c|c|c|c|}
\hline Auxin & 0.5 & 1 & 2 & 5 & 10 \\
\hline IAA & & & & & \\
\hline IBA & $30^{*}, 120^{* *}$ & 30,120 & 30 & & \\
\hline NAA & 30 & 30 & 30 & & 30 \\
\hline 2,4-D & 30 & 30 & 30 & 30 & 30 \\
\hline Dicamba & & 30,120 & 30 & 30,120 & \\
\hline Picloram & & 30 & 30 & \\
\hline
\end{tabular}

\section{Microscopic observations}

For assessing the embryonic nature of the spherical structures resulted on culture medium with 2,4-D, dicamba and picloram, the accumulation of starch and lipid reserves was used as indicator. For staining the starch granules, randomly selected globular structures resulted from the initial explants were prepared after the method described by Yeung (1998) with a minor modification, the tissue was squashed between the microscope slide and the cover slip in a drop of Lugol solution instead of being sectioned. Alternatively, for staining of the oil bodies, Sudan IV was used following the method described by Yeung (1998). The observations were made using the inverted microscope (Olympus CK-2).

\section{Data collection and analysis}

The cultures were observed weekly and at the 2nd and 4th weeks pictures were taken under stereomicroscope using a digital camera (Canon PowerShot A400). The percentage of explants showing 
morphogenesis (organogenesis or embryogenesis) was calculated for each treatment. To assess organogenesis the regeneration of buds from pre-existing meristems (apical/axillary shoots) or de novo induction of adventitious buds were recorded. Each treatment had tree replicates with the exception of treatments with 120 $\mathrm{g} \mathrm{L}^{-1}$ sucrose where only two replicates were performed and each replicate consisted in 10 explants. Data were analyzed by t-test using R statistical software (Free Software Foundation's GNU General Public License). Significance for all statistical comparisons was set at $\mathrm{p} \leq 0.05$.

\section{Results}

A-PL, resulted from ungerminated sunflower mature zygotic embryo, was used for selective induction of organogenesis or somatic embryogenesis. This is a complex explant containing the apical meristem and the two primordial leaves (Figure 1d). The competence for regenerating apical / axillary shoots, adventitious buds or somatic embryos was acquired only in the presence of exogenously supplied auxins and only in the explants containing the apical meristem and primordial leaves together (A-PL), as a unit. The explant wounding prevents the induction of any morphogenetic response. A specific type of regeneration could be triggered by applying a certain auxin. According to the response induced in the explants, the auxins, regardless of their concentration in the culture medium containing $30 \mathrm{~g} \mathrm{~L}^{-1}$ sucrose, were divided in two groups, AIO comprising IAA, IBA and NAA and AIE which include 2,4-D, dicamba and picloram. Induction of apical / axillary shoots

On AIO containing medium, the morphogenesis was possible from the pre-existing meristems, resulting one apical and / or two axillary primary shoots (Figure 2a - c). After two weeks in culture, the apical / axillary shoots (Figure 2c) showed regeneration with the highest efficiency on medium supplemented with $0.5 \mathrm{mg} \mathrm{L}^{-1}$ for each auxin belonging to AIO type. Up to $70 \%$ of the explants produced shoots on medium containing IAA (Table 2).). It was important not to detach the apical / axillary shoots from the explants, for many of the treatments the adventitious buds being induced on their stem (Figure 2a).

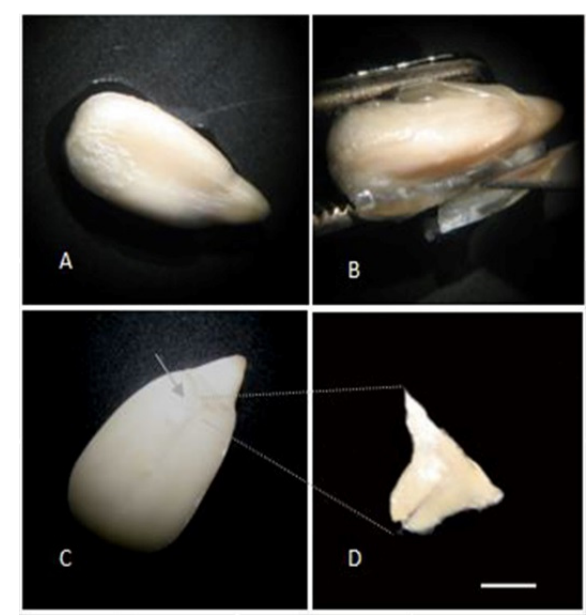

Figure 1. Preparation of the A-PL explant: mature sunflower seed (A), seed coat removal (B), seed after removal of one of the cotyledons, the A-PL is indicated by an arrow (C), A-PL, detail (D); bar - $200 \mu \mathrm{m}$ 

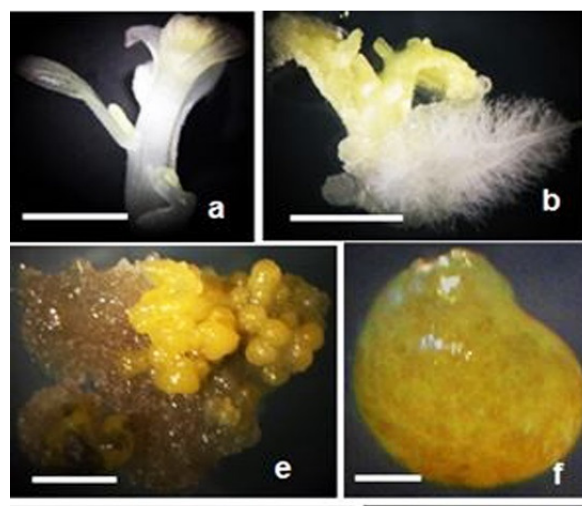

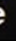
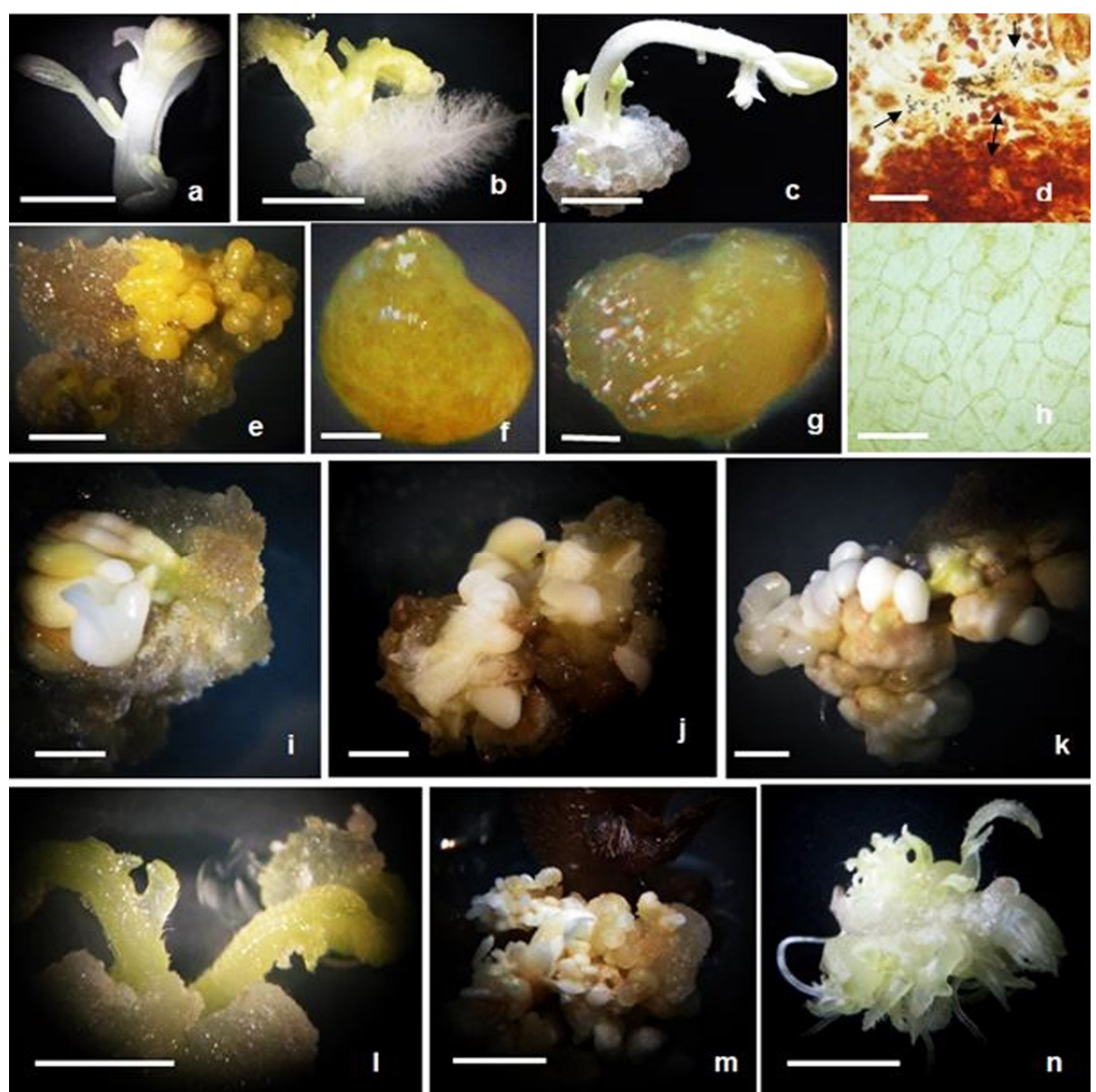

Figure 2. Morphogenesis of sunflower A-PL under different auxin treatments on normal (a-h) and high (i-n) sucrose concentrations: axillary shoot developed on the apical plantlet resulted after 4 weeks under 1 $\mathrm{mg} \mathrm{L}^{-1}$ IAA treatment (a); adventitious buds on the primary leaves lamina for two weeks on $1 \mathrm{mg} \mathrm{L}^{-1} \mathrm{IBA}$ (b); one apical and two axillary primary shoots developed after 4 weeks treatment with $2 \mathrm{mg} \mathrm{L}^{-1} \mathrm{IBA}$ (c); embryonic cells presenting oil bodies stained in red with Sudan IV (double arrow) and large callus cells with blue-black starch granules stained with Lugol (arrow) (d); somatic embryos in early regeneration stage (two weeks) on $5 \mathrm{mg} \mathrm{L}^{-1}$ 2,4-D (e); detail of advanced globular (f) and cordiform embryos (g); epidermal cell monolayer of the cordiform embryo $(\mathbf{h})$; mature embryos resulted after 4 weeks culture on high sucrose concentration under $1 \mathrm{mg} \mathrm{L}^{-1}$ 2,4-D (i), $5 \mathrm{mg} \mathrm{L}^{-1}$ picloram (j), and $2 \mathrm{mg} \mathrm{L}^{-1}$ dicamba treatments $(\mathbf{k})$; adventitious buds on $1 \mathrm{mg} \mathrm{L}^{-1}$ IAA (1), cotyledons-like structures on $0.5 \mathrm{mg} \mathrm{L}^{-1} \mathrm{IAA}(\mathbf{m})$, leaves on $0.5 \mathrm{mg}$ $\mathrm{L}^{-1}$ IAA (n) resulted on medium containing $120 \mathrm{~g} \mathrm{~L}^{-1}$ sucrose ; $\operatorname{Bar} 100 \mu \mathrm{m}(\mathrm{d}, \mathrm{h}), 300 \mu \mathrm{m}(\mathrm{f}, \mathrm{g}), 3 \mathrm{~mm}(\mathrm{i}, \mathrm{j}$, $\mathrm{k}), 5 \mathrm{~mm}(\mathrm{c}, \mathrm{e}, 1, \mathrm{~m}, \mathrm{n}), 1 \mathrm{~cm}(\mathrm{a}, \mathrm{b})$

\section{Induction of adventitious buds}

Two weeks later, the induction of the adventitious buds was assessed. Among the AIO, IAA gave the best response regarding the frequency of explants regenerating adventitious buds for all the tested concentrations $\left(0.5,1\right.$, and $\left.2 \mathrm{mg} \mathrm{L}^{-1}\right)$, followed by 0.5 and $1 \mathrm{mg} \mathrm{L}^{-1} \mathrm{IBA}$. These results were significantly better ( $\mathrm{t}$-test, $\mathrm{p}<0.05)$ compared with those obtained on medium with NAA (Table 2 ). The buds were located also on the leaf lamina (Figure $2 \mathrm{~b}$ ) or on the petiole of the grown primordial leaves (Figure 2l) with no specificity in regard to auxin type, excepting the adventitious buds induced by NAA which were not regenerated on the leaf lamina at all. Although callus was obtained under different AIO treatments (results not presented here) no indirect shoot regeneration occurred. 
Table 2. The effect of AIO (IAA, IBA, NAA) on sunflower A-PL organogenesis - from pre-existing meristems and induced de novo

\begin{tabular}{|c|c|c|}
\hline $\begin{array}{l}\text { Auxin concentration } \\
\quad\left(\mathrm{mg} \mathrm{L}^{-1}\right)\end{array}$ & $\begin{array}{l}\text { Explants forming apical / axillary shoots } \\
\qquad(\% \pm S E)\end{array}$ & $\begin{array}{l}\text { Explants forming adventitious buds } \\
\qquad(\% \pm S E)\end{array}$ \\
\hline Control (no auxin) & $0 \mathrm{a}$ & $0 \mathrm{a}$ \\
\hline \multicolumn{3}{|l|}{ IAA } \\
\hline 0.50 & $\begin{array}{l}70.0 \pm 0.0 \mathrm{~b} \\
\underline{19.5 \pm 0.0} \\
\end{array}$ & $\begin{array}{c}52.5 \pm 9.6 \mathrm{~b} \\
\underline{0}\end{array}$ \\
\hline 1.00 & $\begin{array}{l}55.0 \pm 2.8 \mathrm{c} \\
\underline{19.5 \pm 0.0}\end{array}$ & $\begin{array}{c}40.0 \pm 12.2 b \\
\underline{5.0 \pm 0.0}\end{array}$ \\
\hline 2.00 & $25.0 \pm 2.8 \mathrm{~d}$ & $45.0 \pm 2.5 \mathrm{~b}$ \\
\hline \multicolumn{3}{|l|}{ IBA } \\
\hline 0.5 & $37.5 \pm 9.6 \mathrm{~cd}$ & $37.5 \pm 7.3 \mathrm{~b}$ \\
\hline 1.0 & $35.0 \pm 8.4 \mathrm{~cd}$ & $40.0 \pm 3.5 b$ \\
\hline 2.0 & $22.5 \pm 7.5 \mathrm{~d}$ & $20.0 \pm 4.7 \mathrm{c}$ \\
\hline \multicolumn{3}{|l|}{ NAA } \\
\hline 0.5 & $66.6 \pm 9.4 b$ & $10.0 \pm 0.0 \mathrm{c}$ \\
\hline 1.0 & $36.6 \pm 4.7 \mathrm{~cd}$ & $3.3 \pm 2.7 \mathrm{~d}$ \\
\hline 2.0 & $23.3 \pm 8.4 \mathrm{~d}$ & $6.6 \pm 5.4 \mathrm{~cd}$ \\
\hline
\end{tabular}

Note: The underlined values resulted on $120 \mathrm{~g} \mathrm{~L}^{-1}$ sucrose treatment. Different letters show significant differences between auxin treatments $(\mathrm{t}$ test, $\mathrm{p}<0.5)$

\section{Induction of somatic embryos}

Supplementation of AIE (2,4-D, dicamba or picloram) in media containing $30 \mathrm{~g} \mathrm{~L}^{-1}$ sucrose, led to the same type of response, the induction of somatic embryos (Table 3, Figure 2e - g). The induction of the embryos occurred mainly indirectly after 3 - 4 weeks of culture from the primordial leaves (Figure 2e). Different concentrations for each AIE were required for embryo induction; on 2,4-D the best response was for the lowest concentrations ( 0.5 and $\left.1 \mathrm{mg} \mathrm{L}^{-1}, \mathrm{p}<0.05\right)$, while for dicamba a higher amount $\left(10 \mathrm{mg} \mathrm{L}^{-1}\right)$ was needed for an efficient embryo induction. Picloram was highly effective at 2 and $5 \mathrm{mg} \mathrm{L}^{-1}, 100 \%$ of the explants regenerating somatic embryos. On 2,4-D and dicamba supplementation, only embryos in the initial developmental stages were obtained (globular and cordiform, Figure 2e - g), while on picloram the embryos developed up to the cotyledonary stage.

\section{The role of supplementation with sucrose}

Based on the fact that in sunflower IZE culture a high sucrose concentration was able to change the fate of morphogenesis (Jeannin et al., 1995) alternatively, for IAA, 2,4-D, dicamba and picloram in concentrations which gave the best results, the role of a high amount of sucrose $\left(120 \mathrm{~g} \mathrm{~L}^{-1}\right)$ on the morphogenetic response of the A-PL was also evaluated. In the presence of IAA $\left(0.5\right.$ and $\left.1 \mathrm{mg} \mathrm{L}^{-1}\right)$ which was the most suitable for inducing apical / axillary shoots development on media containing $30 \mathrm{~g} \mathrm{~L}^{-1}$ sucrose, shoots resulted only sporadically on medium containing high amount of sucrose (Table 2). In the same time, the induction of the adventitious buds was almost inhibited (Table 2). A high sucrose concentration led instead to the formation of leaves or to structures similar in appearance with the cotyledons (white and thickened) (Figure $2 \mathrm{l}-\mathrm{n}$ ). No embryos with a normal structure were obtained (Figure $2 \mathrm{l}-\mathrm{n}$ ). When a high sucrose concentration was used simultaneously with AIE treatment, the development of embryos up to the cotyledonary stage was promoted (Figure $2 \mathrm{i}-\mathrm{k}$, Table 3). 
Table 3. The effect of AIE (2,4-D, dicamba, picloram) on sunflower A-PL embryogenesis after 4 weeks in culture

\begin{tabular}{|c|c|}
\hline $\begin{array}{c}\text { Auxin concentration } \\
\left(\mathrm{mg} \mathrm{L}^{-1}\right)\end{array}$ & $\begin{array}{c}\text { Explants forming embryos } \\
(\% \pm \mathrm{SE})\end{array}$ \\
\hline Control (No auxin) & $0 \mathrm{a}$ \\
\hline $2,4-\mathrm{D}$ & $\begin{array}{c}97.5 \pm 2.1 \mathrm{~b} \\
85.0 \pm 14.5\end{array}$ \\
\hline 1.0 & $93.3 \pm 5.4 \mathrm{~b}$ \\
\hline 2.0 & $67.5 \pm 8.1 \mathrm{c}$ \\
\hline 5.0 & $40.0 \pm 15.8 \mathrm{c}$ \\
\hline 10.0 & \\
\hline Dicamba & $10.0 \pm 5.7 \mathrm{~d}$ \\
\hline 1.0 & $55.0 \pm 25.9 \mathrm{bc}$ \\
\hline 2.0 & $\underline{40.0 \pm 10.5}$ \\
\hline 5.0 & $60.0 \pm 23.0 \mathrm{bc}$ \\
\hline 10.0 & $85.0 \pm 2.8 \mathrm{bc}$ \\
\hline Picloram & \\
\hline 2.0 & $100 \pm 0.0 \mathrm{~b}$ \\
\hline 5.0 & $100 \pm 0.0 \mathrm{~b}$ \\
\hline
\end{tabular}

Note: The underlined values resulted on $120 \mathrm{~g} \mathrm{~L}^{-1}$ sucrose treatment. Different letters show significant differences between auxin treatments $(\mathrm{t}$ test, $\mathrm{p}<0.5)$

\section{Discussion}

In preliminary trials the induction of a morphogenetic response in the sunflower A-PL resulted from ungerminated mature embryo was tested on culture media supplemented with different cytokinins (6benzylaminopurine, kinetin or zeatin). No morphological structures compatible with plant regeneration (buds or somatic embryos) were obtained; in the best case only, leaves were regenerated on medium containing cytokinins (data not shown).

This study shows that A-PL requires exogenously applied auxins for gaining the morphogenetic potential. Organogenesis or somatic embryogenesis could be selectively induced by certain auxin treatments. In the experimental system established in this study IAA, IBA and NAA were AIO and 2,4-D, dicamba and picloram were AIE. On AIO, depending on the type of auxin the growth of apical and/or two axillary primary shoots was obtained, most probably directly from the pre-existing meristems similar to the culture of embryonic axis in which shoot morphogenesis was induced by preconditioning the explants on medium containing cytokinin (Konov et al., 1998), or directly in the presence of cytokinin (Hewezi et al., 2003). The most important aspect is the induction of adventitious shoot which was achieved in over $50 \%$ of the explants, on the best regenerating media containing $0.5 \mathrm{mg} \mathrm{L}^{-1}$ IAA This value can be considered very good in term of efficiency for sunflower morphogenesis, in several reports only a reduced number of explants responding in culture (Finer, 1987; Espinasse et al., 1989). On the contrary, on picloram treatment the embryo's induction frequency reached $100 \%$. Maintaining continuously the explants on the AIE led to proliferation of the embryos, which remained in the globular or cordiform stages when 2,4-D and dicamba were used, and developed up to the cotyledonary stage in case of using medium with picloram. 
Until now, the only sunflower explants in which a specific type of regeneration could be induced in a controlled manner were represented by those resulted from IZE (Bronner et al., 1994; Jeannin et al., 1995; Jeannin et al., 1998). The main factor involved in targeting a specific type of regeneration in IZE, was the osmolarity of the medium due to the concentration of sucrose. On high osmotic condition somatic embryos were induced, while on low osmotic medium shoots were obtained (Jeannin et al., 1995). Compared to our results when regeneration was possible only in the presence of exogenously auxin, in the IZE culture the exogenously supplied auxin was not required for inducing a certain response, the presence of cytokinin as a solely growth regulator being mandatory for regeneration (Charriere and Hahne, 1998). By adding auxin, the response could be modified in relation to the osmolarity of the medium in the IZE (Charriere and Hahne, 1998). The requirement for auxin can be related to the developmental stage of the explants. In early stages of the IZE the endogenous auxin is synthesized in high concentrations, whereas during the embryo maturation lower concentrations were reported (Michalski, 1969). This could explain why in IZE the morphogenetic potential can be achieved without exogenous auxin supply, while the auxin is needed for getting similar results in mature embryo derived tissues. Indeed, the endogenous auxin participation was directly (Thomas et al., 2002) or indirectly (Charriere and Hahne, 1998) proven in somatic embryo induction in sunflower IZE culture on media free of auxins.

Gaining the regeneration potential in sunflower was a continuous challenge and during time several protocols were established. For the majority of the methods the auxin was an important component of the culture media. Regardless of their type, somatic embryos or shoots were induced, the regeneration pathway being more related to other factors, the type of the explant having the highest influence on the way of the morphogenesis. Somatic embryos were induced by different auxins, IAA (Charriere and Hahne, 1998), NAA (Patterson and Everett, 1985; Pelissier et al., 1990; Fiore et al., 1997; Charriere and Hahne, 1998), 2,4-D (Finer, 1987; Sujatha and Prabakaran, 2001), dicamba (Finer, 1987) and picloram (Jayabalan and Chandrasekar, 2007), mostly in IZE derived tissues. In the same way, buds were developed under different auxin treatment: IAA (Nataraja and Ganapathi, 1989; Sujatha et al., 2012), NAA (Power, 1987; Knittel et al., 1991, Sujatha and Prabakaran, 2001; Hewezi et al., 2003; Zhang and Finer, 2015), IBA (Nataraja and Ganapathi, 1989) and 2,4-D (Ozyigit et al., 2007). Among the AIE, 2,4-D and dicamba were more appropriate for inducing somatic embryos from IZE (Finer, 1987). On the contrary, in the present study picloram led to the best results regarding both, the efficiency of regeneration (100\%) and the development of somatic embryos, mature embryos being obtained on the induction medium. Among the AIO, IAA led to the best response regarding the both processes involving organogenesis - induction of the adventive meristems and shoot development, when primary shoots grow from the pre-existing meristems.

Although in vitro sunflower regeneration was induced in tissues of different origin, there is only one reference for using primordial leaves as explants resulted directly from germinated seeds with no other pretreatments (Shin et al., 2000). In that case the regeneration occurred via organogenesis on auxin free medium, while the presence of auxin significantly decreased the morphogenetic response (Shin et al., 2000). The explants used in the present study become competent for regeneration only if auxin was supplemented in the culture medium. In this case, adventitious buds were induced on the primordial leaves which are part of a more complex explant, A-PL, derived from ungerminated embryos. This difference in response can be related to the developmental stage of the embryos. It could be explained by the fact that the germinated embryos have a high amount of endogenous auxin (Ni et al., 2001) which can promote the first steps of regeneration. Another way of inducing the potential for regeneration in sunflower young leaves was by preconditioning the growth of the generating explants on medium containing cytokinin (Konov et al., 1998; Zhang and Finer, 2015).

The high osmolarity of the culture medium, modulated by sugar supply can be one of the most important factors responsible for inducing somatic embryogenesis in sunflower (Jeannin et al., 1995). Among the sugars tested sucrose showed the highest regeneration efficiency (Jeannin et al., 1995; Sujatha and Prabakaran, 2001). In our case, on low sucrose concentration $\left(30 \mathrm{~g} \mathrm{~L}^{-1}\right)$, either shoots or somatic embryos were 
158

obtained, the auxin being the key factor for the determination of the morphogenetic response. On high sucrose concentration medium ( $\left.120 \mathrm{~g} \mathrm{~L}^{-1}\right)$, although the type of regeneration wasn't changed in relation to AIO or AIE, the embryogenesis was sustained in the sense that the embryos developed on AIE up to the cotyledonary stage. On the IAA, even if no embryo was obtained, several cotyledon-like structures were induced, which suggests that using A-PL, a high sucrose concentration works exclusively as promoter of the embryo maturation by increasing the accumulation of the reserve substances rather than as an inducer of embryogenesis (Businge et al., 2013).

The accumulation of the reserve substances is a prerequisite for somatic embryogenesis (Merkle et al., 1995). To assess if the spherical structures that were obtained are true somatic embryos we looked for the presence of the starch granules since, in sunflower protoplasts, a positive correlation between the proportion of cells containing starch and the subsequently morphogenetic callus was found (Laparra et al., 1997). No starch granules were present in the cells of the embryos, but they were rich in oil bodies (Fig. 2d). This was not surprising since during sunflower in planta IZE development the sugars are readily directed toward the fatty acid synthesis (Alonso et al., 2007). The oil bodies weren't present in the callus cells surrounding the group of the embryos. Moreover, starch granules were spotted in the non-morphogenetic large cells of the callus, only. The epidermis of the embryos (Figure 2h), one of the first sign of embryonic organization (Finer, 1987), was also distinguished. Based on our findings, the presence of the oil bodies can be considered an indicator of the early embryogenesis stages in sunflower and they can be easily seen even without a specific staining. Squashing technique presents the advantage that is fast and informative enough, allowing the study of unicellular layers but the quality of the images is not that high (Figure 2d). The maintenance of the explants in the dark was beneficial for inducing embryogenesis as was highlighted already for sunflower in vitro culture (Fiore et al., 1997).

By achieving the selective induction of the somatic embryos or buds in sunflower tissue culture this method may offer a good starting point for the development of an efficient protocol for plant regeneration. Further studies are necessary to demonstrate if this plasticity in the response which appears to be under the control of auxins is genotype dependent or is more related to the explant type.

\section{Conclusions}

Using a new type of explants for sunflower in vitro culture - A-PL, resulted from ungerminated mature embryos, the competence for somatic embryogenesis or caulogenesis can be efficiently induced by certain auxins. IAA and IBA were the most favourable auxins for inducing organogenesis, whereas picloram was the most efficient for inducing embryogenesis. A high sucrose concentration used in combination with EIA promoted the development and maturation of the embryos. The advantage of starting from ungerminated mature embryos is that the method is simple and fast - no germination or preconditioning is needed for acquiring the competence for morphogenesis. The mature seeds are available all year round, so the drawback of using IZE, which are difficult to obtain is overcome.

\section{Acknowledgements}

This work was supported by the Sectorial Operational Program for Human Resources Development 2007-2013, co-financed by the European Social Fund, under the project number POSDRU/159/1.5/S/132400 with the title „Young successful researchers - professional development in an international and interdisciplinary environment". The publication was supported by funds from the National Research Development Projects to finance excellence (PFE)-37/2018-2020 granted by the Romanian Ministry of Research and Innovation. 


\section{Conflict of Interests}

The authors declare that there are no conflicts of interest related to this article.

\section{References}

Alonso AP, Goffman FD, Ohlrogge JB, Shachar-Hill Y (2007). Carbon conversion efficiency and central metabolic fluxes in developing sunflower (Helianthus annuus L.) embryos. Plant Journal 52(2):296-308.

Bronner R, Jeannin G, Hahne G (1994). Early cellular events during organogenesis and somatic embryogenesis induced on immature zygotic embryos of sunflower (Helianthus annuus). Canadian Journal of Botany 72(2):239-248.

Businge E, Bygdell J, Wingsle G, Moritz T, Egertsdotter U (2013). The effect of carbohydrates and osmoticum on storage reserve accumulation and germination of Norway spruce somatic embryos. Physiologia Plantarum 149(2):273-285.

Charriere F, Hahne G (1998). Induction of embryogenesis versus caulogenesis on in vitro cultured sunflower (Helianthus annuus L.) immature zygotic embryos: role of plant growth regulators. Plant Science 137(1):63-71.

Christianson ML, Warnick DA (1983). Competence and determination in the process of in vitro shoot organogenesis. Developmental Biology 95(2):288-293.

Dhaka N, Kothari SL (2002). Phenylacetic acid improves bud elongation and in vitro plant regeneration efficiency in Helianthus annuus L. Plant Cell Report 21(1):29-34.

Espinasse A, Lay C, Volin J (1989). Effect of growth regulator concentration and explant size on shoot organogenesis from callus derived from zygotic embryos of sunflower (Helianthus annuus L). Plant Cell Tissue and Organ Culture 17(2-3):171181.

Finer JJ (1987). Direct somatic embryogenesis and plant regeneration from immature embryos of hybrid sunflower (Helianthus annuus L.) on high sucrose-containing medium. Plant Cell Report 6(5):372-374.

Fiore MC, Trabace T, Sunseri F (1997). High frequency of plant regeneration in sunflower from cotyledons via somatic embryogenesis. Plant Cell Report 16(5):295-298.

Freyssinet M, Freyssinet G (1988). Fertile plant regeneration from sunflower (Helianthus annuus L) immature embryos. Plant Science 56(2):177-181.

Hewezi T, Jardinaud F, Alibert J, Kallerhoff J (2003). A new approach for efficient regeneration of a recalcitrant genotype of sunflower (Helianthus annuus L.) by organogenesis induction on split embryonic axes. Plant Cell Tissue and Organ Culture 73(1):81-86.

Jayabalan N, Chandrasekar BR (2007). In vitro plant regeneration through somatic embryogenesis of sunflower (Helianthus annuus L.) for crop improvement. Journal for the Theory of Social Behaviour 56:327-332.

Jeannin G, Bronner R, Hahne G (1995). Somatic embryogenesis and organogenesis induced on the immature zygotic embryo of sunflower (Helianthus annum L.) cultivated in vitro: role of the sugar. Plant Cell Report 15(3-4):200-204.

Jeannin G, Charriere F, Bronner R, Hahne G (1998). Is predetermined cellular competence required for alternative embryo or shoot induction on sunflower zygotic embryos? Botanica Acta 111(4):280-286.

Knittel N, Escandon AS, Hahne G (1991). Plant regeneration at high frequency from mature sunflower cotyledons. Plant Science 73(2):219-226.

Konov A, Bronner R, Skryabin K, Hahne G (1998). Formation of epiphyllous buds in sunflower (Helianthus annuus L.): induction in vitro and cellular origin. Plant Science 135(1):77-86.

Kumar P, Srivastava DK (2015). Biotechnological applications in in vitro plant regeneration studies of broccoli (Brassica oleracea L. var. italica), an important vegetable crop. Biotechnology Letters 38(4):561-571.

Laparra H, Bonner R, Hahne G (1997). Amyloplasts as a possible indicator of morphogenic potential in sunflower protoplasts. Plant Science 122(2):183-192.

Lewi DM, Hopp HE, Escandón AS (2006). Sunflower (Helianthus annuus L.). Methods in Molecular Biology 343:291-297.

Merkle SA, Parrott WA, Flinn BS (1995). Morphogenic aspects of somatic embryogenesis. In: Thorpe TA (Ed). In vitro embryogenesis in plants. Dordrecht, Kluwer Academic pp 155-203. 
160

Michalski L (1969). Content of plant growth regulators in the developing seeds of oak (Quercus robur L.). II Auxin like substances. Acta Societatis Botanicorum Poloniae 38(1):157-163.

Murashige T, Skoog F (1962). A revised medium for rapid growth and bioassay with tobacco tissue culture. Physiologia Plantarum 15:473-497.

Nagy JI, Maliga P (1976). Callus induction and plant regeneration from mesophyll protoplasts of Nicotiana sylvestris. Zeitschrift fur Pflanzenphysiologie 78(5):453-455.

Nataraja K, Ganapathi TR (1989). In vitro plant regeneration from cotyledons of Helianthus annuus cv. Morden (sunflower). Indian Journal of Experimental Biology 27:777-779.

Ni DA., Wang LJ, Ding CH, Xu ZH (2001). Auxin distribution and transport during embryogenesis and seed germination in Arabidopsis. Cell Research 11(4):273-278.

Ozyigit II, Bajrovic K, Gozukirmizi N, Semiz BD (2002). Direct plant regeneration from hypocotyl and cotyledon explants of five different sunflower genotypes (Helianthus annuus L.) from Turkey. Biotechnology \& Biotechnical Equipment 16(1):8-11.

Ozyigit II, Gozukirmizi N, Semiz BD (2007). Genotype dependent callus induction and shoot regeneration in sunflower (Helianthus annuus L.). African Journal of Biotechnology 6(13):1498-1502.

Paterson KE (1984). Shoot tip culture of Helianthus annuus - flowering and development of adventitious and multiple shoots. American Journal of Botany 71(7):925-931.

Paterson KE, Everett NP (1985). Regeneration of Helianthus annuus inbred plants from callus. Plant Science 42(2):125-132.

Pelissier B, Bouchefra O, Pepin R, Freyssinet G (1990). Production of isolated somatic embryos from sunflower thin cell layer. Plant Cell Report 9(1):47-50.

Potrykus I (1990). Gene transfer to cereals: an assessment. Nature Biotechnology 8:535-542.

Power CJ (1987). Organogenesis from Helianthus annuus inbreds and hybrids from the cotyledons of zygotic embryos. American Journal of Botany 74(4):497-503.

Radonic LM, Lewi DM, López NE, Hopp HE, Escandón AS, Bilbao ML (2015). Sunflower (Helianthus annuus L.). Methods in Molecular Biology 1224:47-55.

Rakosy-Tican E, Aurori A, Vesa S, Kovacs K-M (2007). In vitro morphogenesis of sunflower (Helianthus annuus) hypocotyl protoplasts: the effects of protoplast density, haemoglobin and spermidine. Plant Cell Tissue and Organ Culture 90(1):55-62.

Shin D-H, Kim JS, Kim IJ, Yang J, Oh SK, Chung GC, Han K-H (2000). A shoot regeneration protocol effective on diverse genotypes of sunflower (Helianthus annuus L.). In Vitro Cellular and Developmental Biology 36(4):273-278.

Sujatha M, Prabakaran AJ (2001). High frequency embryogenesis in immature zygotic embryos of sunflower. Plant Cell Tissue and Organ Culture 65(1):23-29.

Sujatha M, Vijay S, Vasavi S, Sivaraj N, Rao SC (2012). Combination of thidiazuron and 2 isopentenyladenine promotes highly efficient adventitious shoot regeneration from cotyledons of mature sunflower (Helianthus annuus L.) seeds. Plant Cell Tissue and Organ Culture 111(3):359-372.

Thomas C, Bronner R, Molinier J, Prinsen E, van Onckelen H, Hahne G (2002). Immuno-cytochemical localization of indole3 -acetic acid during induction of somatic embryogenesis in cultured sunflower embryos. Planta 215(4):577-583.

Yeung E (1998). A beginner's guide to the study of plant structure. In: Karcher SJ (ed) Tested studies for laboratory teaching. Proceedings of the $19^{\text {th }}$ Workshop/Conference of the Association for Biology Laboratory Education (ABLE), pp 125142.

Zhang Z, Finer JJ (2015). Sunflower (Helianthus annuus L.) organogenesis from primary leaves of young seedlings preconditioned by cytokinin. Plant Cell Tissue and Organ Culture 123(3):645-655.

Witrzens B, Scowcroft WR, Downes RW, Larkin PJ (1988). Tissue culture and plant regeneration from sunflower (Helianthus annuus) and interspecific hybrids (H. tuberosus $\mathrm{x}$ H. annuus). Plant Cell Tissue and Organ Culture 13(1):61-76. 
Aurori A et al. (2020). Not Bot Horti Agrobo 48(1):150-161.

OPEN ACCESS

(c) (i)

The journal offers free, immediate, and unrestricted access to peer-reviewed research and scholarly work. Users are allowed to read, download, copy, distribute, print, search, or link to the full texts of the articles, or use them for any other lawful purpose, without asking prior permission from the publisher or the author.

License - Papers published in Notulae Botanicae Horti Agrobotanici Cluj-Napoca are Open-Access, distributed under the terms and conditions of the Creative Commons Attribution (CC BY) License.

(c) Articles by the authors; UASVM, Cluj-Napoca, Romania. The journal allows the author(s) to hold the copyright/to retain publishing rights without restriction. 